\title{
Microstructure of Copper-Graphite-Alumina Powders Produced by High-Energy Milling
}

\author{
I. Rodrigues ${ }^{*}$, M. Guedes ${ }^{* * * * * * *}$, A. C. Ferro ${ }^{* * * * * * * *}$
}

*Instituto Superior Técnico, ULisboa, Av. Rovisco Pais, 1049-001 Lisboa, PORTUGAL.

** Department of Mechanical Engineering, School of Technology, Instituto Politécnico de Setúbal, 2910-761 Setúbal, PORTUGAL.

*** Department of Mechanical Engineering, Instituto Superior Técnico, ULisboa, 1049-001 Lisboa, PORTUGAL.

**** ICEMS, Instituto Superior Técnico, Av. Rovisco Pais, 1049-001 Lisboa, PORTUGAL.

Email : mafalda.guedes@estsetubal.ips.pt

Copper alloys and composites are versatile materials used in electrical, tribological and mechanical applications. Because they present high electrical and thermal conductivity, high corrosion resistance and sufficiently high melting point, they have extensive use in applications such as electrical switches, contactors, circuit breakers and relays, among other microelectromechanical systems. The useful lifetime of such devices is shortened by repetitive contact, where continual making and breaking of an electrical circuit accelerates cold weld effects and mechanical disturbance on metallic contact points. Development of robust solutions combining low wear and low electrical loss is thus of paramount importance to the thermal management and electromechanical industries.

Under this perspective graphite is apparently an excellent reinforcement solution for copper, because of its low coefficient of thermal expansion, high strength, high conductivity and self-lubricating ability. Several graphite-fiber and graphite-particulate copper reinforced composites are commercially used, mainly produced by the powder technology route [1]. However further application is hindered by the low thermal and electrical conductivity resulting from resistance at the copper/graphite interface.

The aim of this work is to improve the composites strength and thermo-electrical performance, while keeping the graphite anti-sticking characteristics. This is approached via powder metallurgy of copper-graphite mixtures in the presence of alumina. Tailored copper-graphite-alumina batches were planetary ball milled up to $16 \mathrm{~h}$, using alumina jars and balls; copper-graphite batches were also prepared under the same conditions to evaluate the effect of contamination from the milling media. Alumina was chosen owing to its high melting point, high hardness, thermal stability and chemical inertness, aiming to promote microstructural grain refinement and uniform introduction of small incoherent strengthening phases. Furthermore, copperalumina composites have almost the same electrical and thermal conductivities as pure copper [2]. The microstructure of the produced materials was characterized by FEG-SEM/EDS and related to Raman, XRD and microhardness results.

During high-energy milling powder particles are repeatedly flattened, cold-welded, fractured and rewelded. In the copper-graphite system the fracture stage is active above $8 \mathrm{~h}$ milling, leading to effective size reduction (Fig. 1). This time reduces to $4 \mathrm{~h}$ in the presence of added alumina (Fig. 2). Nonetheless, alumina is present in resulting material from both systems, due to contamination from the milling media. Produced powders are nanostructured, containing graphite and alumina nanoparticles homogeneously distributed in copper, especially for longer milling times and in the presence of added alumina (Fig. 3). Increasing milling time results in nanographite amorphization and size decrease, as attested by Raman data (Fig. 4). Copper crystallite size and lattice parameter are only affected above $8 \mathrm{~h}$ milling. 
[1] Guler O. et al., J. Mater. Process. Tech. 209, 1286-1290, 2009.

[2] Tian, B. et al., Mater. Sci. Eng. A 435-436, 705-710, 2006.
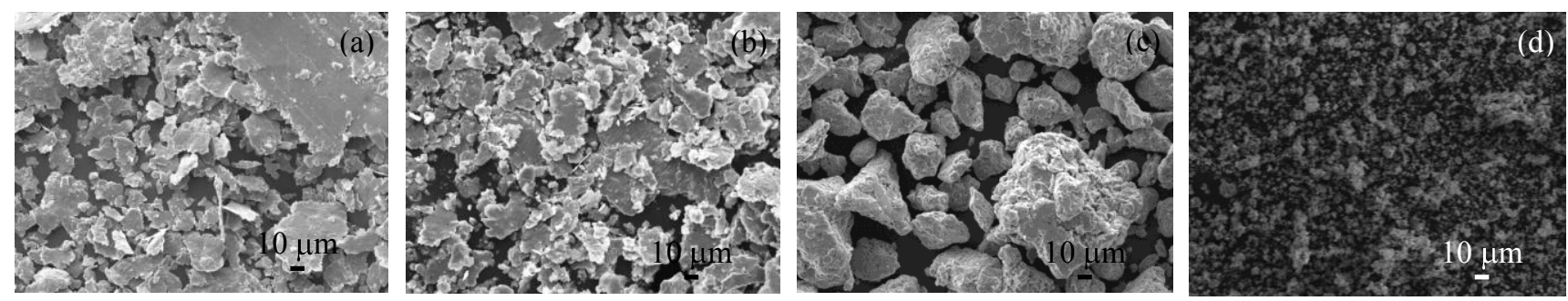

Figure 1. Low magnification SEI of copper-graphite particles achieved after milling for: (a) 2 h; (b) 4 h; (c) 8 $\mathrm{h}$ and (d) $16 \mathrm{~h}$.
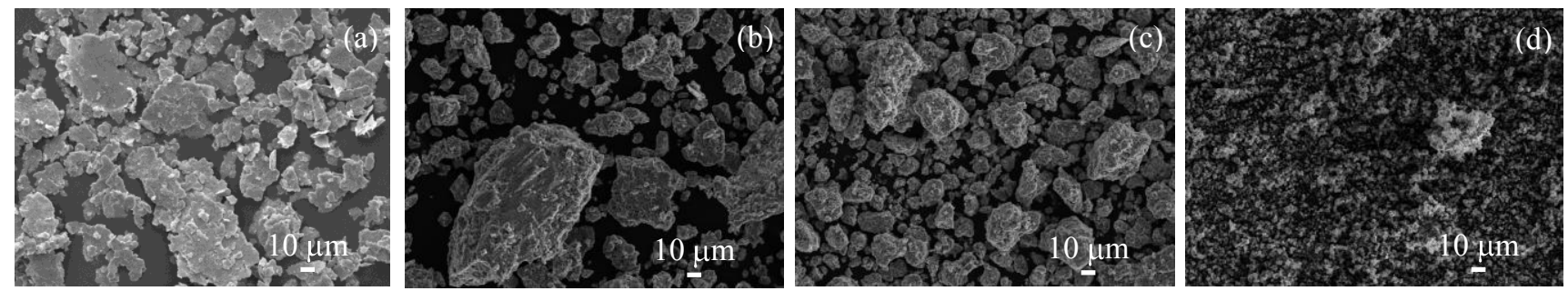

Figure 2. Low magnification SEI of copper-graphite-alumina particles achieved after milling for: (a) $2 \mathrm{~h}$; (b) $4 \mathrm{~h}$; (c) $8 \mathrm{~h}$ and (d) $16 \mathrm{~h}$.
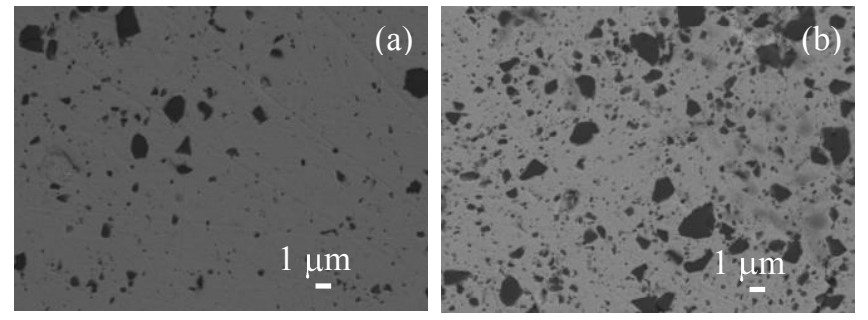

Figure 3. BEI of powders produced after milling for 8h: (a) copper-graphite; (b) copper-graphitealumina.

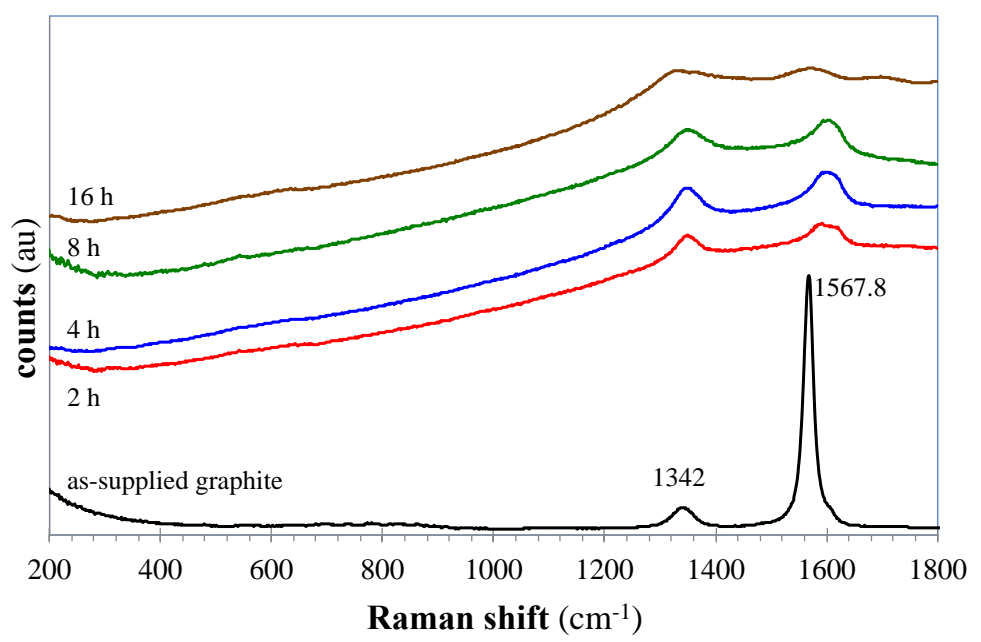

Figure 4. Raman spectra of copper-graphite-alumina powders after variable milling time. 